\title{
Central role of carotid body chemoreceptors in disordered breathing and cardiorenal dysfunction in chronic heart failure
}

\author{
Noah J. Marcus ${ }^{1 *}$, Rodrigo Del Rio ${ }^{2}$ and Harold D. Schultz ${ }^{1}$ \\ ${ }^{1}$ Department of Cellular and Integrative Physiology, University of Nebraska Medical Center, Omaha, NE, USA \\ ${ }^{2}$ Laboratory of Cardiorespiratory Control, Center of Biomedical Research, Universidad Autónoma de Chile, Santiago, Chile
}

Edited by:

Geoffrey A. Head, Baker IDI Heart and Diabetes Institute, Australia

Reviewed by:

Fiona D. McBryde, University of Auckland, New Zealand

Man Lung Fung, The University of Hong Kong, China

\section{${ }^{*}$ Correspondence:}

Noah J. Marcus, Department of Cellular and Integrative Physiology, University of Nebraska Medical

Center, 985850 Nebraska Medical Center, Omaha, NE 68198-5850,

USA

e-mail:nmarcus@unmc.edu
Oscillatory breathing $(\mathrm{OB})$ patterns are observed in pre-term infants, patients with cardio-renal impairment, and in otherwise healthy humans exposed to high altitude. Enhanced carotid body (CB) chemoreflex sensitivity is common to all of these populations and is thought to contribute to these abnormal patterns by destabilizing the respiratory control system. OB patterns in chronic heart failure (CHF) patients are associated with greater levels of tonic and chemoreflex-evoked sympathetic nerve activity (SNA), which is associated with greater morbidity and poor prognosis. Enhanced chemoreflex drive may contribute to tonic elevations in SNA by strengthening the relationship between respiratory and sympathetic neural outflow. Elimination of $\mathrm{CB}$ afferents in experimental models of $\mathrm{CHF}$ has been shown to reduce $\mathrm{OB}$, respiratory-sympathetic coupling, and renal $\mathrm{SNA}$, and to improve autonomic balance in the heart. The CB chemoreceptors may play an important role in progression of $\mathrm{CHF}$ by contributing to respiratory instability and $\mathrm{OB}$, which in turn further exacerbates tonic and chemoreflex-evoked increases in SNA to the heart and kidney.

Keywords: carotid body chemoreceptors, Cheyne-Stokes respiration, sympathetic nervous system, heart failure, cardiorenal syndrome

\section{INTRODUCTION}

Abnormal oscillatory breathing (OB) patterns are frequently observed in diverse populations, including infants born prematurely (Copeman et al., 1964), patients with heart failure (Ponikowski et al., 1999), or end stage renal disease (Hanly and Pierrato, 2001), and in otherwise healthy humans who travel to high altitude (Lahiri et al., 1983). These abnormal breathing patterns most commonly occur during non-REM sleep when chemical control of breathing predominates; however, some heart failure patients exhibit $\mathrm{OB}$ during waking hours as well (Brack et al., 2007). OB is characterized by oscillations in tidal volume and/or respiratory frequency and is thought to occur as a result of physiological or environmental challenges that de-stabilize the respiratory control system. These challenges may include alterations in arterial blood gases and $\mathrm{pH}$ (decreased $\mathrm{P}_{\mathrm{a}} \mathrm{O}_{2}$, decreased $\mathrm{P}_{\mathrm{a}} \mathrm{CO}_{2}$, and increased $\mathrm{pH}$ ), circulatory delay and reductions in systemic oxygen transport, and enhancement of respiratory chemoreflex function (Fanfulla et al., 1998). The etiology of OB is diverse; however a significant body of research indicates that enhanced chemoreflex sensitivity is a common element of most types of OB (Lahiri et al., 1983; Ponikowski et al., 1999; Al-Matary et al., 2004; Nock et al., 2004; Hering et al., 2007).

\section{CHEMOREFLEX SENSITIVITY AND DISORDERED BREATHING IN HEART FAILURE}

Cheyne-Stokes respiration (CSR), a form of OB in which oscillations in tidal volume are separated by apneic episodes, is highly prevalent in patients with chronic heart failure (CHF) (Mortara et al., 1997; Ponikowski et al., 1999; Giannoni et al., 2008). CSR is associated with increased morbidity and mortality, and decreased quality of life in this population (Hanly and Zuberi-Khokhar, 1996; Lanfranchi et al., 1999; Brack et al., 2007; Carmona-Bernal et al., 2008). Accumulating evidence suggests that enhanced central and/or peripheral chemoreflex sensitivity (Javaheri, 1999; Narkiewicz et al., 1999; Giannoni et al., 2008) as well as persistent hyperventilation/hypocapnia (Naughton et al., 1993; Fanfulla et al., 1998) contribute to the pathogenesis of CSR by causing instability of the respiratory control system (Naughton et al., 1993; Lorenzi-Filho et al., 1999, 2005; Pinna et al., 2000). The significance of the relationship between chemosensitivity and CSR is further underscored by the finding that high peripheral chemosensitivity is independently associated with poor prognosis and higher mortality risk in CHF patients but not in comparable CHF patients with low chemosensitivity (Ponikowski et al., 1999, 2001).

Numerous studies indicate that carotid body (CB) chemoreceptor-mediated responses to hypoxia and hypercapnia are augmented in CHF (Wilcox et al., 1993; Chua et al., 1996, 1997; Javaheri, 1999; Ponikowski and Banasiak, 2001; Ciarka et al., 2006; Giannoni et al., 2008). In a group of 60 CHF patients, approximately $60 \%$ had increased $\mathrm{CB}$ chemoreflex sensitivity (Giannoni et al., 2008). Most importantly, patients without augmented chemosensitivity did not exhibit CSR, and the incidence of CSR progressively 
increased with enhancement of the $\mathrm{CB}$ chemoreflex. In other studies, deactivation of $\mathrm{CB}$ chemoreceptors with transient hyperoxia, or pharmacological attenuation of chemosensitivity with dihydrocodeine or acetazolamide significantly reduced central apnea incidence in CHF patients (Ponikowski et al., 1999; Fontana et al., 2011). These findings indicate an important relationship between CSR or cyclical breathing patterns and enhanced $\mathrm{CB}$ chemoreflex sensitivity.

Recent studies in animal models of CHF have further delineated the role of the CB chemoreceptors in OB. Studies from our laboratory have demonstrated enhanced ventilatory, sympathetic nerve, and carotid sinus nerve responses to isocapnic hypoxia as well as a tonic increase in resting afferent chemoreceptor discharge during normoxia in both rabbit and rat models of heart failure (Sun et al., 1999a,b; Li et al., 2005; Del Rio et al., 2013b; Haack et al., 2014; Marcus et al., 2014a). These increases in $\mathrm{CB}$ chemoreceptor activity coincide with an increase in measures of $\mathrm{OB}$ and the development of $\mathrm{CHF}$ (Marcus and Schultz, 2011). Denervation of the CB chemoreceptors (CBD) by $\mathrm{CB}$ ablation after the development of $\mathrm{CHF}$ results in abolition of chemoreflex responses, reduction of resting ventilation and sympathetic nerve activity (SNA), and reduction of apnea/hypopnea frequency and respiratory variability (Del Rio et al., 2013b; Marcus et al., 2014a). In other studies, pharmacologic attenuation of $\mathrm{CB}$ chemoreceptor activity with Simvastatin or an inhibitor of hydrogen sulfide production had similar efficacy in reducing apnea/hypopnea frequency and respiratory variability (Del Rio et al., 2013a; Haack et al., 2014).

Ablation of CB afferent activity in the aforementioned studies (Del Rio et al., 2013b; Marcus et al., 2014a) resulted in significant reductions in resting ventilation, which in turn would be expected to increase resting $\mathrm{PaCO}_{2}$. CHF-CBD rabbits exhibited significant hypoventilation relative to normal animals for up to 9 days post CBD, the endpoint of the study (Marcus et al., 2014a). CHF-CBD rats exhibited hypoventilation compared to the ventilatory parameters obtained in normal animals when measured 2 days post denervation, but no hypoventilation was found at 14 weeks post CBD (Del Rio et al., 2013b). Thus, the salutary effect of CBD to stabilize the respiratory pattern in CHF could stem from an increase in $\mathrm{P}_{\mathrm{a}} \mathrm{CO}_{2}$ above the apneic threshold, at least in the short-term, but abrogation of the elevated ventilatory loop gain mediated by the CB chemoreflex is likely to play an important role in reestablishing respiratory stability in $\mathrm{CHF}$ in the long-term.

Resting ventilation and sympathetic outflow are increased in CHF (Naughton et al., 1993; van de Borne et al., 1998). In our studies, CBD-reduced resting sympathetic outflow as well as ventilation, indicating that $\mathrm{CB}$ chemoreceptors play an important role in the tonic increases in both of these parameters in $\mathrm{CHF}$. Central neural coupling between respiratory and sympathetic neural drive has been described in the literature (Haselton and Guyenet, 1989). It is possible that the elevated tonic input from $\mathrm{CB}$ chemoreceptors exacerbates respiratory-sympathetic coupling to account in part for their marked increase in $\mathrm{CHF}$ patients.

\section{RESPIRATORY-SYMPATHETIC COUPLING IN HEART FAILURE}

It is well-known that sympathetic discharge is actively modulated by respiration (Adrian et al., 1932; Haselton and Guyenet, 1989), and a growing body of evidence indicates that this modulatory influence may be altered in several different pathological states. Evidence of enhanced respiratory-sympathetic coupling has been found in three different animal models of hypertension (Zoccal et al., 2008; Simms et al., 2009; Toney et al., 2010) with differing etiologies (spontaneously hypertensive rat-SHR, Ang II/salt, and chronic intermittent hypoxia-CIH). Interestingly, in two of these models ( $\mathrm{SHR}$ and $\mathrm{CIH}$ ), enhanced CB chemoreflex sensitivity and tonic $\mathrm{CB}$ chemoreceptor afferent input to the brain stem have been shown to play a seminal role in mediating increased SNA and the development of hypertension (Fletcher et al., 1992; Peng et al., 2003; Del Rio et al., 2010; Marcus et al., 2010; Tan et al., 2010; Abdala et al., 2012). Furthermore, sympathetic drive increases in tandem with respiratory neural output after exposure to CIH (Zoccal et al., 2008). No studies have examined CB chemoreflex tone in the Ang II/salt model, however Ang II has been shown to play a role in enhancing CB chemosensitivity (Li et al., 2006), and thus it is plausible that tonic $\mathrm{CB}$ chemoreceptor input is elevated in this model as well. Evidence from these studies suggests that enhanced afferent activity arising from the CBs promotes respiratorysympathetic coupling that in turn perpetuates sympathetic over activity.

Recent work from our lab (Figure 1) has shown that respiratory-sympathetic coupling is enhanced in $\mathrm{CHF}$, and that the enhanced coupling coincides with sensitization of the $\mathrm{CB}$ chemoreflex (Marcus et al., 2014a). Furthermore, we demonstrated that respiratory-sympathetic coupling in CHF is critically dependent on the $\mathrm{CB}$ since it was markedly reduced or abolished after CBD (Marcus et al., 2014a). Taken together, these findings strongly suggest a central role for enhanced tonic CB chemoreceptor drive in the development of respiratory-sympathetic coupling in disease conditions characterized by autonomic imbalance and abnormal respiratory rhythms.

The mechanisms underpinning the relationship of $\mathrm{CB}$ chemoreflex drive to respiratory-sympathetic coupling in $\mathrm{CHF}$ are still unclear. A plausible hypothesis is that the entrainment between the respiratory and sympathetic neural drive may result from alterations in the neurons integrating $\mathrm{CB}$ afferents and initiating respiratory rhythm and sympathetic outflow in the brainstem. Indeed, there is evidence that $\mathrm{CIH}$-induced sympatho-excitation results in an increase in the strength of the excitatory synapses at the level of the nucleus of the solitary tract, the paraventricular nucleus, and the rostral medulla (Kc et al., 2010; Kline, 2010; Silva and Schreihofer, 2011; CostaSilva et al., 2012). Enhanced respiratory-sympathetic coupling is of major relevance in CHF patients in which hyperventilation is common, and in which frequent respiratory oscillations occur during CSR (Figure 1). Previous investigators have observed surges in SNA during the hyperpneic phase of CSR (Leung et al., 2006) which may be indicative of enhanced respiratory-sympathetic coupling, and which likely has important impact on downstream targets such as the heart and kidneys. 


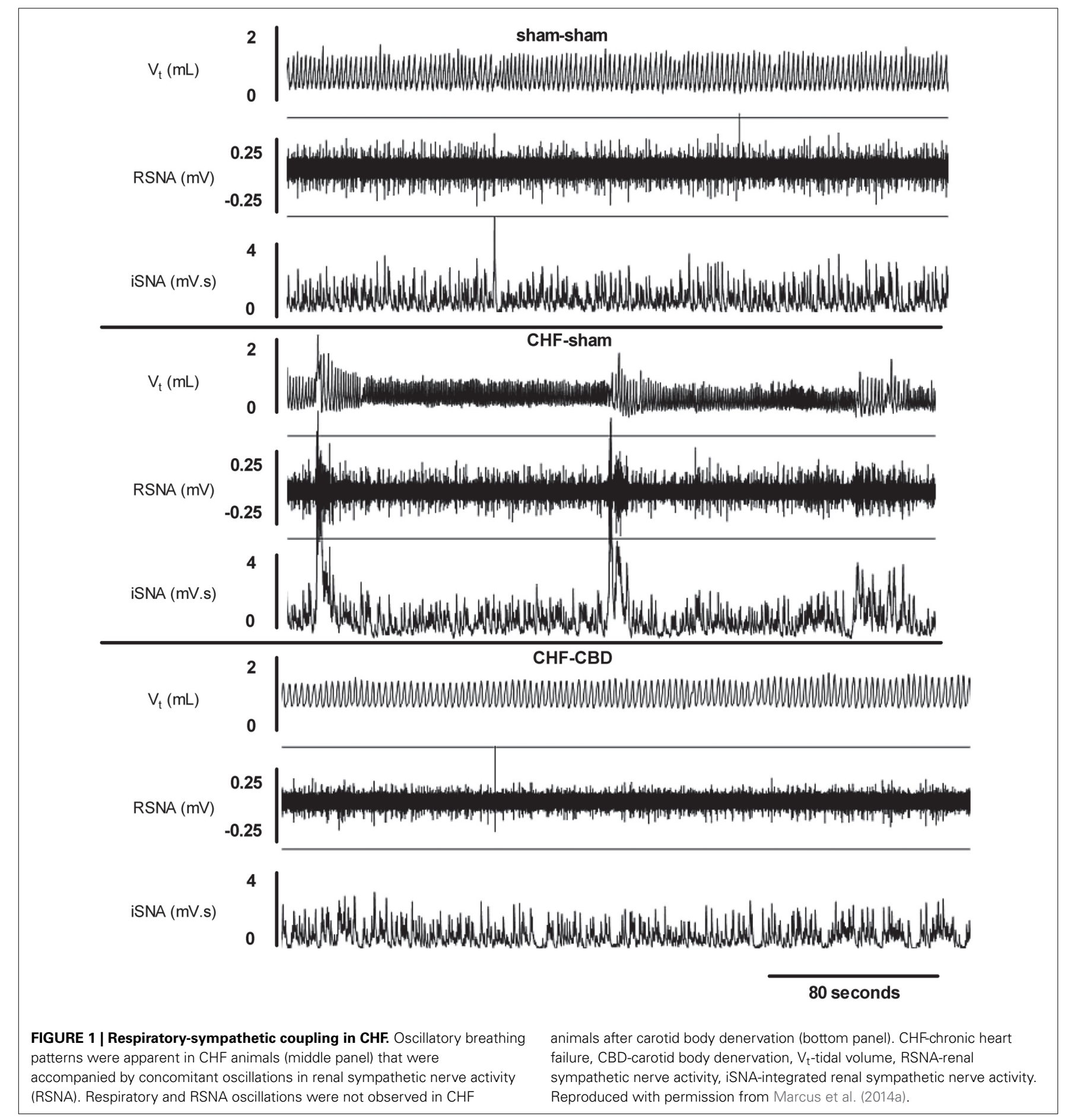

\section{ROLE OF ENHANCED CHEMOREFLEX SENSITIVITY AND DISORDERED BREATHING IN CARDIAC AND RENAL DYSFUNCTION IN HEART FAILURE}

In CHF patients, renal dysfunction is common and is associated with poor prognosis (Bock and Gottlieb, 2010). Development of renal dysfunction in CHF is particularly ominous because it can precipitate further decline in cardiac function, initiating a downward spiral of deteriorating cardiac and renal function, known as cardiorenal syndrome. While the etiology of cardiorenal syndrome is diverse, excessive sympathetic activation, volume retention and venous congestion, renal ischemia secondary to reductions in renal perfusion, and neuro-hormonal activation are thought to play central roles (Bock and Gottlieb, 2010). Tonic chemoreflex activation in CHF may contribute to cardiorenal syndrome by increasing sympathetic stimulation of the heart (Xing et al., 2014) and kidneys (Sun et al., 1999a) leading to increases 
in peripheral vascular resistance and myocardial oxygen demand, increases in sodium and water retention, and activation of the renin-angiotensin system. In addition, the development of $\mathrm{OB}$ mediated by enhanced $\mathrm{CB}$ chemoreflex sensitivity may further exacerbate renal ischemia by eliciting additional chemoreflexevoked renal vasoconstriction in addition to episodic hypoxemia (Figure 1).

Under normal circumstances, CB chemoreflex activation elicits a reduction in renal blood flow and glomerular filtration rate that is mediated by renal sympathetic nerves (Karim et al., 1987). In CHF, tonic elevations in renal SNA mediate sustained reductions in renal blood flow and alterations in angiotensin signaling (Clayton et al., 2011). Our preliminary findings indicate that the reduction in renal blood flow to $\mathrm{CB}$ chemoreflex activation is markedly accentuated in CHF animals. Further, CBD in $\mathrm{CHF}$ animals reduces renal SNA, increases renal blood flow, and decreases markers of renal injury and fibrosis (Marcus et al., $2014 b$ ), in addition to the reduction in disordered breathing and improvement in cardiac function mentioned previously (Marcus et al., 2014a). These findings suggest that tonic CB chemoreflex activation in CHF may contribute to renal pathology in part by its influence on sympathetic outflow (Hering et al., 2007) to the heart and kidneys (Sun et al., 1999b; Xing et al., 2014). In addition to the influence of tonic $\mathrm{CB}$ chemoreflex activation on resting renal SNA, additional surges in SNA may be superimposed by episodic hypoxemia associated with apneic episodes during sleep (van de Borne et al., 1998), augmented by an enhanced $\mathrm{CB}$ chemoreceptor sensitivity to hypoxia in CHF (Marcus et al., 2014a). This notion is supported by evidence from studies in clinical populations (Ryan et al., 2005).

Normalization of abnormal breathing patterns in $\mathrm{CHF}$ patients with continuous positive airway pressure (CPAP) or

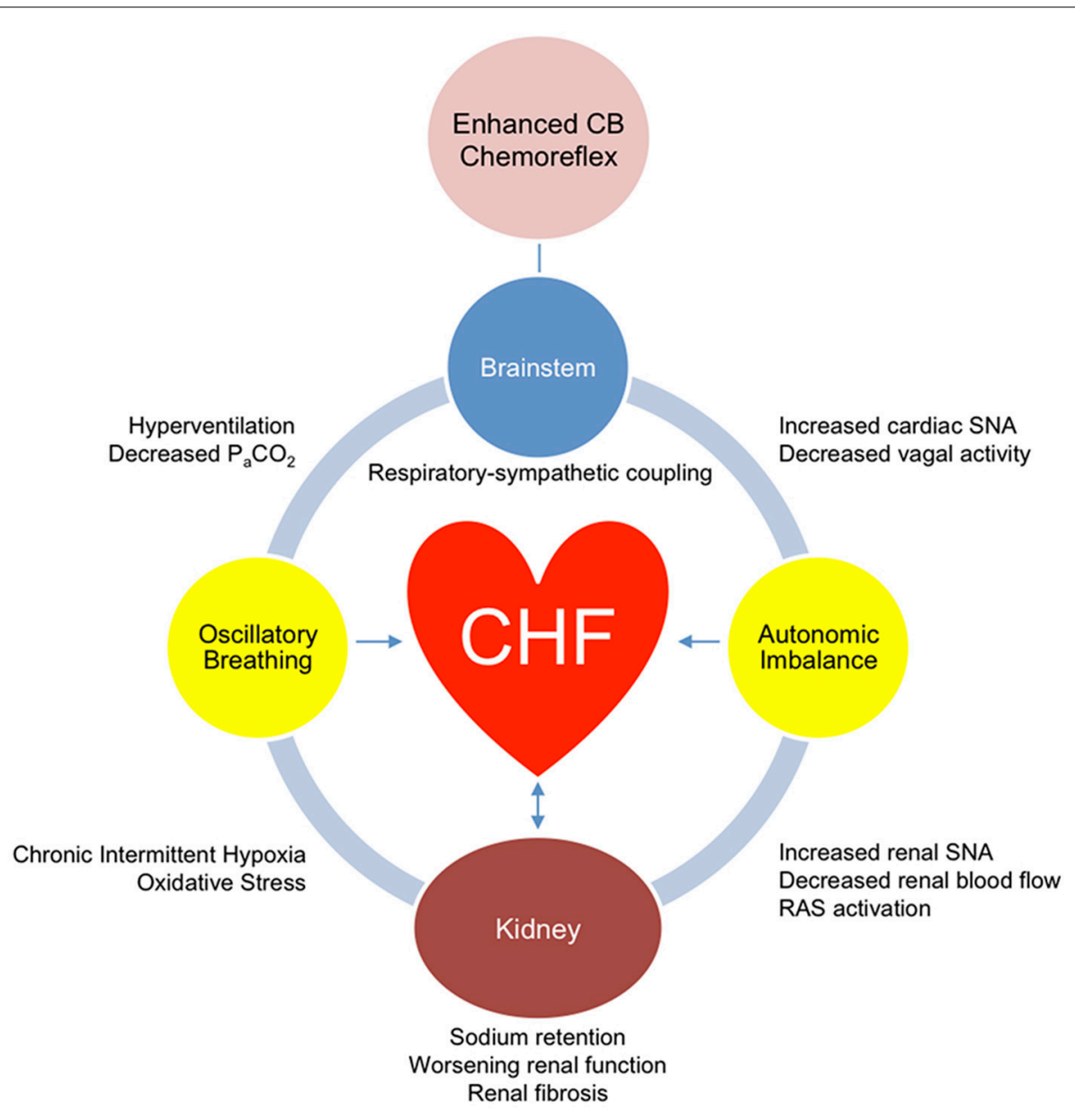

FIGURE 2 | Role of carotid body chemoreceptors in cardiac and renal dysfunction. Enhanced tonic afferent activity from carotid body (CB) chemoreceptors drives neuronal activity in brainstem centers that integrate peripheral afferents and control respiratory and sympathetic neural outflow. Hyperventilation due to the enhanced CB chemoreflex activation precipitates oscillatory breathing, which exacerbates sympathetic activation through respiratory-sympathetic coupling, in addition to exposing the heart and kidneys to intermittent hypoxia and oxidative stress. The CB-mediated enhanced respiratory-sympathetic coupling results in increased sympathetic and decreased vagal efferent outflow to the heart, which over time worsens cardiac function and development of fibrosis. Similarly, CB-mediated increases in renal SNA cause reductions in renal perfusion and activation of the renin-angiotensin system (RAS), which over time lead to worsening renal function and development of fibrosis. The combined deleterious effects of CB-mediated respiratory-sympathetic coupling on the heart and kidney advances the cardiorenal syndrome. 
adaptive servo-ventilation (ASV) is associated with reduced tonic levels of sympathetic activation (Ryan et al., 2005), improved cardiac function, improved renal function, and improved prognosis (Koyama et al., 2011; Yoshihisa et al., 2011; Kasai et al., 2013; Owada et al., 2013). These improvements may be due to secondary effects of CPAP or ASV treatments to improve cardiac function via direct mechanical effects of pressure support ventilation on the heart (Takama and Kurabayashi, 2011), however they also likely reflect the reduction in CB chemoreflex sensitivity (Spicuzza et al., 2006), and consequent reduction in $\mathrm{CB}$ chemoreflex-mediated sleep disordered breathing and sympathoexcitation (Naughton et al., 1995; Despas et al., 2009). Our findings in an animal model of CHF support this notion of the functional consequences of enhanced respiratorysympathetic coupling in CHF mediated by the $\mathrm{CB}$. The reduction of disordered breathing patterns with $\mathrm{CBD}$ was sufficient to reduce renal SNA, increase renal blood flow, and improve cardiac function (Marcus et al., 2014a,b) and survival (Del Rio et al., 2013b), independent of any confounding effects of pressure support ventilation used in the aforementioned clinical studies.

\section{CONCLUSION}

Accumulating evidence suggests a critical role for the $\mathrm{CB}$ chemoreceptors in the etiology of several important pathophysiological aspects of CHF. CB chemoreceptors are a major driving force in the development of autonomic dysfunction and breathing abnormalities in CHF. Ablation of the $\mathrm{CB}$ chemoreceptors is sufficient to improve these parameters and leads to improved cardiac function (Marcus et al., 2014a) and survival (Del Rio et al., 2013b). The mechanisms by which the CB chemoreflex exacerbates cardiac deterioration and morbidity in $\mathrm{CHF}$ remain to be better elucidated, but disordered breathing, enhanced respiratory-sympathetic coupling, tonic and episodic increases in cardiac and renal SNA, and reductions in renal function likely play an important role (Figure 2). A case report published recently showed that unilateral CBD in a CHF patient resulted in modest improvements in autonomic function, cardiac function, and exercise tolerance, and reduced resting ventilation (Niewinski et al., 2013). This study supports findings from pre-clinical animal models and confirms the potential of CBD or other forms of CB modulation as a therapeutic option in CHF patients. Taken together, these findings suggest that CB-mediated disordered breathing and respiratory-sympathetic coupling in CHF plays an important role in the abnormalities of sympathetic outflow observed in CHF with negative clinical implications for cardiac and renal function (Marcus et al., 2014a,b).

\section{ACKNOWLEDGMENTS}

Noah J. Marcus is supported by a National Research Service Award fellowship from the Heart, Lung and Blood Institute of NIH (F32-HL108592-01A1). Rodrigo Del Rio is funded by Fondo Nacional de Desarrollo Científico y Tecnológico (Fondecyt \#1140275) and Harold D. Schultz is funded by a Program Project Grant from the Heart, Lung and Blood Institute of NIH (PO1-HL62222).

\section{REFERENCES}

Abdala, A. P., McBryde, F. D., Marina, N., Hendy, E. B., Engelman, Z. J., Fudim, M., et al. (2012). Hypertension is critically dependent on the carotid body input in the spontaneously hypertensive rat. J. Physiol. 90, 4269-4277. doi: 10.1113/jphysiol.2012.237800

Adrian, E. D., Bronk, D. W., and Phillips, G. (1932). Discharges in mammalian sympathetic nerves. J. Physiol. 74, 115-133.

Al-Matary, A., Kutbi, I., Qurashi, M., Khalil, M., Alvaro, R., Kwiatkowski, K., et al. (2004). Increased peripheral chemoreceptor activity may be critical in destabilizing breathing in neonates. Semin. Perinatol. 28, 264-272. doi: 10.1053/j.semperi.2004.08.003

Bock, J. S., and Gottlieb, S. S. (2010). Cardiorenal syndrome: new perspectives. Circulation 121, 2592-2600. doi: 10.1161/CIRCULATIONAHA.109.886473

Brack, T., Thuer, I., Clarenbach, C. F., Senn, O., Noll, G., Russi, E. W., et al. (2007). Daytime Cheyne-Stokes respiration in ambulatory patients with severe congestive heart failure is associated with increased mortality. Chest 132, 1463-1471. doi: 10.1378/chest.07-0121

Carmona-Bernal, C., Ruiz-Garcia, A., Villa-Gil, M., Sanchez-Armengol, A., Quintana-Gallego, E., Ortega-Ruiz, F., et al. (2008). Quality of life in patients with congestive heart failure and central sleep apnea. Sleep Med. 9, 646-651. doi: 10.1016/j.sleep.2007.11.008

Chua, T. P., Ponikowski, P., Webb-Peploe, K., Harrington, D., Anker, S. D., Piepoli, M., et al. (1997). Clinical characteristics of chronic heart failure patients with an augmented peripheral chemoreflex. Eur. Heart J. 18, 480-486. doi: 10.1093/oxfordjournals.eurheartj.a015269

Chua, T. P., Ponikowski, P. P., Harrington, D., Chambers, J., and Coats, A. J. (1996). Contribution of peripheral chemoreceptors to ventilation and the effects of their suppression on exercise tolerance in chronic heart failure. Heart 76, 483-489. doi: $10.1136 /$ hrt.76.6.483

Ciarka, A., Cuylits, N., Vachiery, J. L., Lamotte, M., Degaute, J. P., Naeije, R., et al. (2006). Increased peripheral chemoreceptors sensitivity and exercise ventilation in heart transplant recipients. Circulation 113, 252-257. doi: 10.1161/CIRCULATIONAHA.105.560649

Clayton, S. C., Haack, K. K., and Zucker, I. H. (2011). Renal denervation modulates angiotensin receptor expression in the renal cortex of rabbits with chronic heart failure. Am. J. Physiol. Renal Physiol. 300, F31-F39. doi: 10.1152/ajprenal.00088.2010

Copeman, P. W., Cowell, T. K., and Dallas, N. L. (1964). Periodic breathing of premature infants. Lancet 7347:1377.

Costa-Silva, J. H., Zoccal, D. B., and Machado, B. H. (2012). Chronic intermittent hypoxia alters glutamatergic control of sympathetic and respiratory activities in the commissural NTS of rats. Am. J. Physiol. Regul. Integr. Comp. Physiol. 302, 785-793. doi: 10.1152/ajpregu.00363.2011

Del Rio, R., Moya, E. A., and Iturriaga, R. (2010). Carotid body and cardiorespiratory alterations in intermittent hypoxia: the oxidative link. Eur. Respir. J. 36, 143-150. doi: 10.1183/09031936.00158109

Del Rio, R., Marcus, N. J., and Schultz, H. D. (2013a). Inhibition of hydrogen sulfide restores normal breathing stability and improves autonomic control during experimental heart failure. J. Appl. Physiol. 114, 1141-1150. doi: 10.1152/japplphysiol.01503.2012

Del Rio, R., Marcus, N. J., Schultz, H. D. (2013b). Carotid chemoreceptor ablation improves survival in heart failure: rescuing autonomic control of cardiorespiratory function. J. Am. Coll. Cardiol. 62, 2422-2430. doi: 10.1016/j.jacc.2013.07.079

Despas, F., Detis, N., Dumonteil, N., Labrunee, M., Bellon, B., Franchitto, N., et al. (2009). Excessive sympathetic activation in heart failure with chronic renal failure: role of chemoreflex activation. J. Hypertens. 9, 1849-1854. doi: 10.1097/HJH.0b013e32832e8d0f

Fanfulla, F., Mortara, A., Maestri, R., Pinna, G. D., Bruschi, C., Cobelli, F., et al. (1998). The development of hyperventilation in patients with chronic heart failure and Cheyne-Strokes respiration: a possible role of chronic hypoxia. Chest 114, 1083-1090. doi: 10.1378/chest.114.4.1083

Fletcher, E. C., Lesske, J., Behm, R., Miller, C. C. 3rd., Stauss, H., and Unger, T. (1992). Carotid chemoreceptors, systemic blood pressure, and chronic episodic hypoxia mimicking sleep apnea. J. Appl. Physiol. 72, 1978-1984.

Fontana, M., Emdin, M., Giannoni, A., Iudice, G., Baruah, R., and Passino, C. (2011). Effect of acetazolamide on chemosensitivity, Cheyne-Stokes respiration, and response to effort in patients with heart failure. Am. J. Cardiol. 107, 1675-1680. doi: 10.1016/j.amjcard.2011.01.060 
Giannoni, A., Emdin, M., Poletti, R., Bramanti, F., Prontera, C., Piepoli, M., et al. (2008). Clinical significance of chemosensitivity in chronic heart failure: influence on neurohormonal derangement, Cheyne-Stokes respiration and arrhythmias. Clin. Sci. (Lond.) 114, 489-497. doi: 10.1042/CS20070292

Haack, K. K., Marcus, N. J., Del Rio, R., Zucker, I. H., and Schultz, H. D. (2014). Simvastatin treatment attenuates increased respiratory variability and apnea/hypopnea index in rats with chronic heart failure. Hypertension 63, 1041-1049. doi: 10.1161/HYPERTENSIONAHA.113.02535

Hanly, P. J., and Pierrato, A. (2001). Improvement of sleep apnea in chronic renal failure treated by nocturnal hemodialysis. N. Engl. J. Med. 344, 102-107. doi: 10.1056/NEJM200101113440204

Hanly, P. J., and Zuberi-Khokhar, N. S. (1996). Increased mortality associated with Cheyne-Stokes respiration in patients with congestive heart failure. Am. J. Respir. Crit. Care Med. 153, 272-276. doi: 10.1164/ajrccm.153.1.8542128

Haselton, J. R., and Guyenet, P. G. (1989). Central respiratory modulation of medullary sympathoexcitatory neurons in rat. Am. J. Physiol. 256, R739-R750.

Hering, D., Zdrojewski, Z., Król, E., Kara, T., Kucharska, W., Somers, V. K., et al. (2007). Tonic chemoreflex activation contributes to the elevated muscle sympathetic nerve activity in patients with chronic renal failure. J. Hypertens. 25, 157-161. doi: 10.1097/HJH.0b013e3280102d92

Javaheri, S. (1999). A mechanism of central sleep apnea in patients with heart failure. N. Engl. J. Med. 341, 949-954. doi: 10.1056/NEJM1999092 33411304

Karim, F., Poucher, S. M., and Summerhill, R. A. (1987). The effects of stimulating carotid chemoreceptors on renal haemodynamics and function in dogs. J. Physiol. 392, 451-462.

Kasai, T., Kasagi, S., Maeno, K., Dohi, T., Kawana, F., Kato, M., et al. (2013). Adaptive servo-ventilation in cardiac function and neurohormonal status in patients with heart failure and central sleep apnea nonresponsive to continuous positive airway pressure. JACC Heart Fail. 1, 58-63. doi: 10.1016/j.jchf.2012.11.002

Kc, P., Balan, K. V., Tjoe, S. S., Martin, R. J., Lamanna, J. C., Haxhiu, M. A., et al. (2010). Increased vasopressin transmission from the paraventricular nucleus to the rostral medulla augments cardiorespiratory outflow in chronic intermittent hypoxia-conditioned rats. J. Physiol. 588, 725-740. doi: 10.1113/jphysiol.2009.184580

Kline, D. D. (2010). Chronic intermittent hypoxia affects integration of sensory input by neurons in the nucleus tractus solitarii. Respir. Physiol. Neurobiol. 174, 29-36. doi: 10.1016/j.resp.2010.04.015

Koyama, T., Watanabe, H., Terada, S., Makabe, S., Igarashi, G., Nobori, K., et al. (2011). Adaptive servo-servo ventilation improves renal function in patients with heart failure. Respir. Med. 105, 1946-1953. doi: 10.1016/j.rmed.2011.09.001

Lahiri, S., Maret, K., and Sherpa, M. G. (1983). Dependence of high altitude sleep apnea on ventilatory sensitivity to hypoxia. Respir. Physiol. 52, 281-301. doi: 10.1016/0034-5687(83)90086-5

Lanfranchi, P. A., Braghiroli, A., Bosimini, E., Mazzuero, G., Colombo, R., Donner, C. F., et al. (1999). Prognostic value of nocturnal CheyneStokes respiration in chronic heart failure. Circulation 99, 1435-1440. doi: 10.1161/01.CIR.99.11.1435

Leung, R. S., Floras, J. S., and Bradley, T. D. (2006). Respiratory modulation of the autonomic nervous system during Cheyne-Stokes respiration. Can. J. Physiol. Pharmacol. 84, 61-66. doi: 10.1139/Y05-145

Li, Y. L., Li, Y. F., Liu, D., Cornish, K. G., Patel, K. P., Zucker, I. H., et al. (2005). Gene transfer of neuronal nitric oxide synthase to carotid body reverses enhanced chemoreceptor function in heart failure rabbits. Circ. Res. 97, 260-267. doi: 10.1161/01.RES.0000175722.21555.55

Li, Y. L., Xia, X. H., Zheng, H., Gao, L., Li, Y. F., Liu, D., et al. (2006). Angiotensin II enhances carotid body chemoreflex control of sympathetic outflow in chronic heart failure rabbits. Cardiovasc. Res. 71, 129-138. doi: 10.1016/j.cardiores.2006.03.017

Lorenzi-Filho, G., Genta, P. R., Figueiredo, A. C., and Inoue, D. (2005). Cheyne-Stokes respiration in patients with congestive heart failure: causes and consequences. Clinics (Sao Paulo) 60, 333-344. doi: 10.1590/S180759322005000400012

Lorenzi-Filho, G., Rankin, F., Bies, I., and Douglas Bradley, T. (1999). Effects of inhaled carbon dioxide and oxygen on cheyne-stokes respiration in patients with heart failure. Am. J. Respir. Crit. Care Med. 159, 1490-1498. doi: 10.1164/ajrccm.159.5.9810040
Marcus, N. J., Del Rio, R., Schultz, E. P., Xia, X. H., and Schultz, H. D. (2014a). Carotid body denervation improves autonomic and cardiac function in congestive heart failure. J. Physiol. 592, 391-408. doi: 10.1113/jphysiol.2013.266221

Marcus, N. J., Del Rio, R., and Schultz, H. D. (2014b). Carotid body denervation reduces renal sympathetic nerve activity and fibrosis, and increases renal blood flow in congestive heart failure. FASEB J. 28, 875.814.

Marcus, N. J., Li, Y. L., Bird, C. E., Schultz, H. D., and Morgan, B. J. (2010). Chronic intermittent hypoxia augments chemoreflex control of sympathetic activity: role of the angiotensin II type 1 receptor. Respir. Physiol. Neurobiol. 171, 36-45. doi: 10.1016/j.resp.2010.02.003

Marcus, N. J., and Schultz, H. D. (2011). Role of carotid body chemoreflex function in the development of Cheyne-Stokes Respiration during progression of congestive heart failure. FASEB J. 25, 841.7.

Mortara, A., Sleight, P., Pinna, G. D., Maestri, R., Prpa, A., La Rovere, M. T., et al. (1997). Abnormal awake respiratory patterns are common in chronic heart failure and may prevent evaluation of autonomic tone by measures of heart rate variability. Circulation 96, 246-252. doi: 10.1161/01.CIR.96.1.246

Narkiewicz, K., Pesek, C. A., van de Borne, P. J., Kato, M., and Somers, V. K. (1999). Enhanced sympathetic and ventilatory responses to central chemoreflex activation in heart failure. Circulation 100, 262-267. doi: 10.1161/01.CIR. 100.3.262

Naughton, M. T., Benard, D. C., Liu, P. P., Rutherford, R., Rankin, F., and Bradley, T. D. (1995). Effects of nasal CPAP on sympathetic activity in patients with heart failure and central sleep apnea. Am. J. Respir. Crit. Care Med. 152, 473-479. doi: 10.1164/ajrccm.152.2.7633695

Naughton, M. T., Benard, D. C., Tam, A., Rutherford, R., and Douglas Bradley, T. (1993). Role of hyperventilation in the pathogenesis of central sleep apneas in patients with congestive heart failure. Am. Rev. Respir. Dis. 148, 330-338. doi: 10.1164/ajrccm/148.2.330

Niewinski, P., Janczak, D., Rucinski, A., Jazwiec, P., Sobotka, P. A., Engelman, Z. J., et al. (2013). Carotid body removal for treatment of chronic systolic heart failure. Int. J. Cardiol. 168, 2506-2509. doi: 10.1016/j.ijcard.2013.03.011

Nock, M. L., DiFiore, J. M., Arko, M. K., and Martin, R. J. (2004). Relationship of the ventilatory response to hypoxia with neonatal apnea in preterm infants. J. Pediatr. 144, 291-295. doi: 10.1016/j.jpeds.2003.11.035

Owada, T., Yoshihisa, A., Yamauchi, H., Iwaya, S., Suzuki, S., Yamaki, T., et al. (2013). Adaptive servo-ventilation improves cardiorenal function and prognosis in heart failure patients with chronic kidney disease and sleep-disordered breathing. J. Card. Fail. 19, 225-232. doi: 10.1016/j.cardfail.2013.03.005

Peng, Y. J., Overholt, J. L., Kline, D., Kumar, G. K., and Prabhakar, N. R. (2003). Induction of sensory long-term facilitation in the carotid body by intermittent hypoxia: implications for recurrent apneas. Proc. Natl. Acad. Sci. U.S.A. 100, 10073-10078. doi: 10.1073/pnas.1734109100

Pinna, G. D., Maestri, R., Mortara, A., La Rovere, M. T., Fanfulla, F., and Sleight, P. (2000). Periodic Breathing in heart failure patients: testing the hypothesis of instability of the chemoreflex loop. J. Appl. Physiol. 89, 2147-2157.

Ponikowski, P., Anker, S. D., Chua, T. P., Francis, D., Banasiak, W., PooleWilson, P. A., et al. (1999). Oscillatory breathing patterns during wakefulness in patients with chronic heart failure: clinical implications and role of augmented peripheral chemosensitivity. Circulation 100, 2418-2424. doi: 10.1161/01.CIR.100.24.2418

Ponikowski, P., and Banasiak, W. (2001). Chemosensitivity in chronic heart failure. Heart Fail. Monit. 1, 126-131.

Ponikowski, P., Chua, T. P., Anker, S. D., Francis, D. P., Doehner, W., Banasiak, W., et al. (2001). Peripheral chemoreceptor hypersensitivity: an ominous sign in patients with chronic heart failure. Circulation 104, 544-549. doi: 10.1161/hc3101.093699

Ryan, C. M., Usui, K., Floras, J. S., and Douglas Bradley, T. (2005). Effect of continuous positive airway pressure on ventricular ectopy in heart failure patients with obstructive sleep apnoea. Thorax 60, 781-785. doi: 10.1136/thx.2005.040972

Silva, A. Q., and Schreihofer, A. M. (2011). Altered sympathetic reflexes and vascular reactivity in rats after exposure to chronic intermittent hypoxia. J. Physiol. 589, 1463-1476. doi: 10.1113/jphysiol.2010.200691

Simms, A. E., Paton, J. F., Pickering, A. E., and Allen, A. M. (2009). Amplified respiratory-sympathetic coupling in the spontaneously hypertensive rat: does it contribute to hypertension? J. Physiol. 587, 597-610. doi: 10.1113/jphysiol.2008.165902

Spicuzza, L., Bernardi, L., Balsamo, R., Ciancio, N., Polosa, R., and Di Maria, G. (2006). Effect of treatment with nasal continuous positive airway pressure on 
ventilatory response to hypoxia and hypercapnia in patients with sleep apnea syndrome. Chest 130, 774-779. doi: 10.1378/chest.130.3.774

Sun, S. Y., Wang, W., Zucker, I. H., and Schultz, H. D. (1999a). Enhanced activity of carotid body chemoreceptors in rabbits with heart failure: role of nitric oxide. J. Appl. Physiol. 86, 1273-1282.

Sun, S. Y., Wang, W., Zucker, I. H., and Schultz, H. D. (1999b). Enhanced peripheral chemoreflex function in conscious rabbits with pacing-induced heart failure. J. Appl. Physiol. 86, 1264-1272.

Takama, N., and Kurabayashi, M. (2011). Effectiveness of adaptive servoventilation for treating heart failure regardless of the severity of sleep-disordered breathing. Circ. J. 75, 1164-1169. doi: 10.1253/circj.CJ-10-0831

Tan, Z. Y., Lu, Y., Whiteis, C. A., Simms, A. E., Paton, J. F., Chapleau, M. W., et al. (2010). Chemoreceptor hypersensitivity, sympathetic excitation, and overexpression of ASIC and TASK channels before the onset of hypertension in SHR. Circ. Res. 106, 536-545. doi: 10.1161/CIRCRESAHA.109.206946

Toney, G. M., Pedrino, G. R., Fink, G. D., and Osborn, J. W. (2010). Does enhanced respiratory-sympathetic coupling contribute to peripheral neural mechanisms of angiotensin II-salt hypertension? Exp. Physiol. 95, 587-594. doi: 10.1113/expphysiol.2009.047399

van de Borne, P., Oren, R., Abouassaly, C., Anderson, E., and Somers, V. K. (1998) Effect of Cheyne-Stokes respiration on muscle sympathetic nerve activity in severe congestive heart failure secondary to ischemic or idiopathic dilated cardiomyopathy. Am. J. Cardiol. 81, 432-436. doi: 10.1016/S0002-9149(97)00936-3

Wilcox, I., Grunstein, R. R., Collins, F. L., Berthon-Jones, M., Kelly, D. T., and Sullivan, C. E. (1993). The role of central chemosensitivity in central apnea of heart failure. Sleep 16, S37-S38.

Xing, D. T., May, C. N., Booth, L. C., and Ramchandra, R. (2014). Tonic arterial chemoreceptor activity contributes to cardiac sympathetic activation in mild ovine heart failure. Exp. Physiol. 99, 1031-1041. doi: 10.1113/expphysiol.2014.079491

Yoshihisa, A., Shimizu, T., Owada, T., Nakamura, Y., Iwaya, S., Yamauchi, H., et al. (2011). Adaptive servo-ventilation improves cardiac dysfunction and prognosis in chronic heart failure patients with Cheyne-Stokes respiration. Int. Heart J. 52, 218-223. doi: 10.1536/ihj.52.218

Zoccal, D. B., Simms, A. E., Bonagamba, L. G., Braga, V. A., Pickering, A. E., Paton, J. F., et al. (2008). Increased sympathetic outflow in juvenile rats submitted to chronic intermittent hypoxia correlates with enhanced expiratory activity. J. Physiol. 586, 3253-3265. doi: 10.1113/jphysiol.2008.154187

Conflict of Interest Statement: The authors declare that the research was conducted in the absence of any commercial or financial relationships that could be construed as a potential conflict of interest.

Received: 01 October 2014; accepted: 27 October 2014; published online: 24 November 2014

Citation: Marcus NJ, Del Rio R and Schultz HD (2014) Central role of carotid body chemoreceptors in disordered breathing and cardiorenal dysfunction in chronic heart failure. Front. Physiol. 5:438. doi: 10.3389/fphys.2014.00438

This article was submitted to Integrative Physiology, a section of the journal Frontiers in Physiology.

Copyright (c) 2014 Marcus, Del Rio and Schultz. This is an open-access article distributed under the terms of the Creative Commons Attribution License (CC BY). The use, distribution or reproduction in other forums is permitted, provided the original author(s) or licensor are credited and that the original publication in this journal is cited, in accordance with accepted academic practice. No use, distribution or reproduction is permitted which does not comply with these terms. 